Check for updates

Cite this: Chem. Commun., 2020,

56,6289

Received 24th March 2020,

Accepted 30th April 2020

DOI: $10.1039 / \mathrm{d} 0 \mathrm{cc} 02158 \mathrm{j}$

rsc.li/chemcomm

\section{Rotation of a helical coordination polymer by mechanical grinding $\dagger$}

\author{
Bibhuti Bhusan Rath, (D) ${ }^{a}$ Goutam Kumar Kole, (D) ${ }^{b}$ Samuel Alexander Morris (D) *c \\ and Jagadese J. Vittal (D) *a
}

Anisotropic cell volume expansion by mechanical grinding of the solid facilitates the concerted rotation of the photo-inert helical coordination polymer, which causes the misaligned arms containing olefin functional groups in the neighbouring strands to align to undergo [2+2] cycloaddition reaction in $83 \%$ yield.

Movements of molecules, especially rotational and vibrational motions are highly restricted in the solid state. However, free space around the functional groups and cooperativity among the molecules in crystals enable large motions of different types. Such molecular dynamics has been observed in molecular crystals as well as in coordination polymers (CPs) and metal-organic frameworks (MOFs) for their potential use in the fabrication of nanoscale devices. ${ }^{1-3}$ Realization of molecular motions resembling gears, gyroscopes and bearings are fascinating advancements in terms of molecular machines. ${ }^{4}$ Further bicycle-pedal or crankshaft motion is the most frequently observed in the solid state. ${ }^{5-14}$ Rotation of helical 1D column of phenylene rotators by the influence of temperature has been studied by Garcia-Garibay et al. ${ }^{15}$

On the contrary, solid state reactions facilitated by grinding, which is popularly called "mechanochemistry", have been extensively explored. ${ }^{16-20}$ Kaupp examined various molecular dynamic processes occurring in the solid state by mechanical forces. ${ }^{21}$ Mechanical pressure upon the motor protein $F_{1}$-ATPase, is known to induce unidirectional motions. ${ }^{22}$ Mechanical force can also cause the molecules to undergo bond stretching to a bond scission. ${ }^{23-25}$ In this manuscript, we describe the influence of mechanical grinding on the molecular rotation of a

\footnotetext{
${ }^{a}$ Department of Chemistry, National University of Singapore, 117543, Singapore. E-mail: chmjjv@nus.edu.sg; Fax: +65-6779-1691

${ }^{b}$ Department of Chemistry and Research Institute, SRM Institute of Science and Technology, Kattankulathur, Tamil Nadu, 603203, India

${ }^{c}$ School of Materials Science and Engineering, Nanyang Technological University, 50 Nanyang Avenue, 639798, Singapore. E-mail: smorris@ntu.edu.sg

$\dagger$ Electronic supplementary information (ESI) available. CCDC 1989895 and 1990101. For ESI and crystallographic data in CIF or other electronic format see DOI: $10.1039 / \mathrm{d} 0 \mathrm{cc} 02158 \mathrm{j}$
}

photostable helical coordination polymer, which causes the misaligned olefin groups in the neighbouring strands to align favourably to undergo solid state photochemical [2+2] cycloaddition reaction (Scheme 1).

The helical coordination polymer, $\left[\left(\mathrm{Ph}_{3} \mathrm{P}\right) \mathrm{Ag}(5-\mathrm{Spym})\left(\mathrm{CF}_{3} \mathrm{SO}_{3}\right)\right]$. $0.75 \mathrm{MeOH}, 1$ was crystallized in the space group $P 2_{1} / n$ with $Z=8$, from a methanolic solution containing $\mathrm{AgCF}_{3} \mathrm{SO}_{3}, \mathrm{PPh}_{3}$ and 5-styrylpyrimidine (5-Spym) by slow evaporation. $\ddagger$ The asymmetric unit contains two $\left[\left(\mathrm{Ph}_{3} \mathrm{P}\right) \mathrm{Ag}(5-\mathrm{Spym})\left(\mathrm{CF}_{3} \mathrm{SO}_{3}\right)\right]$ units and 1.5 MeOH. The crystal readily loses methanol from its lattice at room temperature and its single crystallinity. The two $\mathrm{Ag}(\mathrm{I})$ atoms have distorted tetrahedral geometry from the phosphorus atom of the $\mathrm{PPh}_{3}$ ligand, an oxygen atom of $\mathrm{CF}_{3} \mathrm{SO}_{3}{ }^{-}$anion, and two nitrogen atoms from two different 5-Spym ligands (Fig. 1a). The connectivity of the 5-Spym ligands to Ag(I) atoms generates helical chains which propagate along $b$-axis (Fig. 1b). The pitch of the [Ag(5-Spym)] helical chain is the length of the $b$-axis, $9.029 \AA$. Further, the 5-Spym arms of the two helical chains arising from two different $\mathrm{Ag}(\mathrm{I})$ atoms are orienting almost normal to each other forming a picket fence enclosing the $\mathrm{PPh}_{3}$ ligands (Fig. 1c).

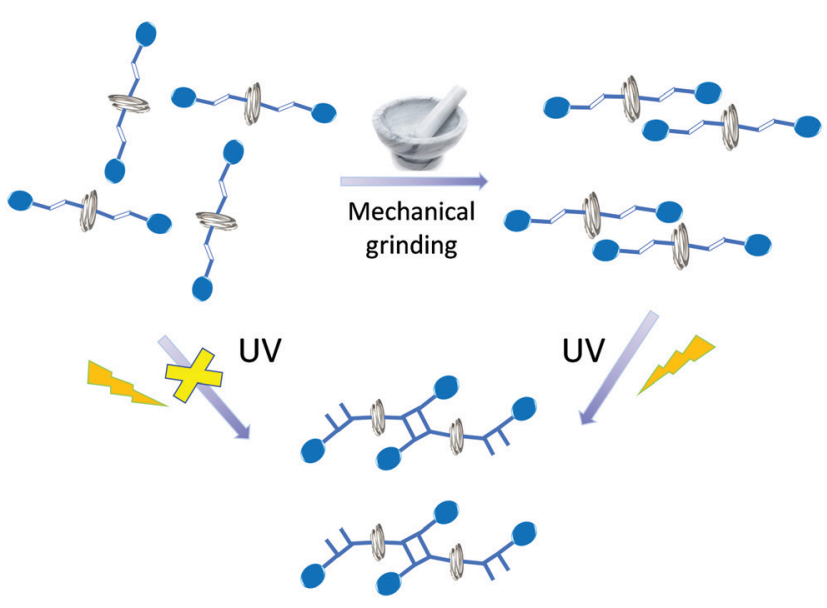

Scheme 1 Rotational motion of helical coordination polymer facilitated by mechanical grinding and dimerization under UV irradiation. 


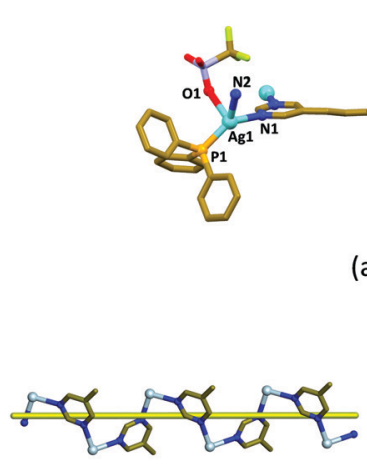

(b)

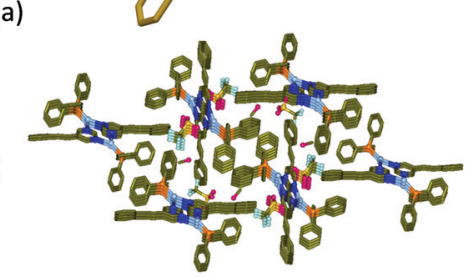

(c)

Fig. 1 (a) Coordination geometry around $\mathrm{Ag}(\mathrm{I})$ atoms with selected labelling of atoms. (b) A helical polymer strand. (c) Packing of 1 showing different orientations of the 5-Spym arms in the helical one-dimensional $\mathrm{CP}$ when viewed from $b$-axis. The disorder and $\mathrm{H}$-atoms are omitted for clarity.

It is evident from the packing that there is no alignment of the olefin pairs between the helical chains satisfying the Schmidt's criteria for [2+2] cycloaddition reaction, ${ }^{26}$ and hence $\mathbf{1}$ is expected to be photo stable. This is also confirmed after exposing the crystals of $\mathbf{1}$ under UV light for a few hours. However, when the crystals were ground to powder using pestle and mortar and then exposed to UV light $\left(\lambda_{\max }=360 \mathrm{~nm}\right)$, the ${ }^{1} \mathrm{H}$-NMR spectrum of the irradiated powder in DMSO- $d_{6}$, showed a multiplet peak centred at $4.76 \mathrm{ppm}$ which indicate to the formation of cyclobutane photoproduct. It is surprising that the photo-inert crystals of $\mathbf{1}$ exhibit photoreactivity after grinding. Henceforth, the $[2+2]$ cycloaddition reactivity was followed with different grinding times. After grinding, the powders were subjected to UV irradiation for $72 \mathrm{~h}$ and the ${ }^{1} \mathrm{H}$-NMR spectra were recorded.

Fig. 2a shows the ${ }^{1} \mathrm{H}$-NMR spectra at different time intervals of UV exposure for the $30 \mathrm{~min}$ ground sample. Gradual disappearance of the proton signals of the pyrimidine group at $9.1 \mathrm{ppm}$, and evolution of the pyrimidine proton peaks at 8.8 and 8.6 as well as the cyclobutane peaks at $c a .4 .76 \mathrm{ppm}$ with different UV exposure time shown in Fig. 2a indicate the progress of the photoreaction. The percentage formation of the cyclobutane photoproduct versus time of UV irradiation in Fig. $2 \mathrm{~b}$ shows a maximum of $83 \%$ conversion of the 5 -Spym ligand to $r c t t-1,3-b i s(5$ '-pyrimidyl)-2,4-bis(phenyl)cyclobutane $(r c t t-b p c b)^{27}$ which could arise only from the head-to-tail alignment in the ground solid. This seems to be accompanied by some side reaction as inferred from the unidentified peaks in the ${ }^{1} \mathrm{H}$-NMR spectra. The dimerization is further complemented by the FT-IR spectral data (Fig. S3, ESI $\dagger$ ). A comparison of the FT-IR spectra between the crystal of $\mathbf{1}$ and ground sample after 30 min grinding shows there is no change in the local coordination mode. For the $30 \mathrm{~min}$ ground sample irradiated under $\mathrm{UV}$ for $25 \mathrm{~h}$, the $\mathrm{C}=\mathrm{C}$ stretching at $1636 \mathrm{~cm}^{-1}$ and $=\mathrm{C}-\mathrm{H}$ out of plane bending at $965 \mathrm{~cm}^{-1}$ were completely disappeared suggesting the conversion of the olefin groups to cyclobutane

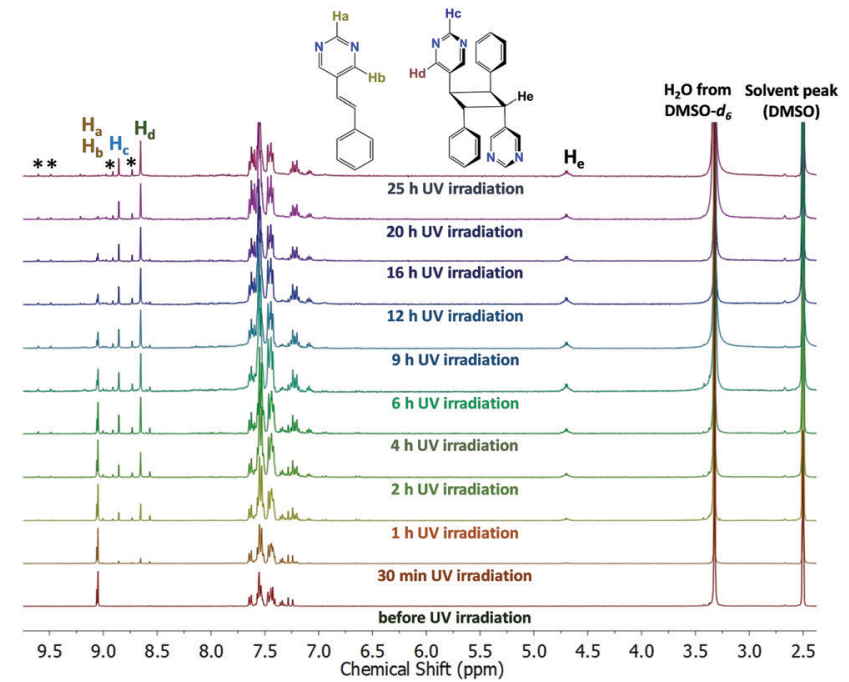

(a)

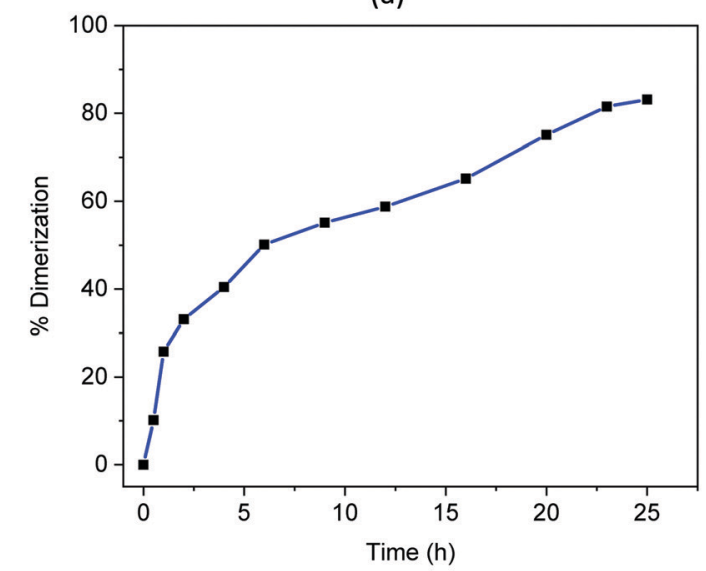

(b)

Fig. 2 (a) ${ }^{1} \mathrm{H}$-NMR spectra of 1 (30 min grinding) in DMSO- $d_{6}$ plotted at different times of UV irradiation. Complete absence of the $\mathrm{H}_{a}, \mathrm{H}_{\mathrm{b}}$ protons may indicate quantitative consumption of the 5-Spym ligand. However, some unidentified peaks indicate only $83 \%$ of rcct-bpcb photoproduct formed. (b) Time-dimerization plot for 30 min ground sample shows the progress of the photoreaction under UV light with time.

group. In order to get further evidence for the head-to-tail dimerization in the photoproduct, $r c t$-bpcb was isolated after chemical treatment and crystallized in DMSO. The single crystal structure of the isolated product clearly validates the head-to-tail dimerization of the ligands.\$

The powder X-ray diffraction (PXRD) patterns in Fig. 3 show that there is a gradual change in crystallinity with increasing grinding time. Broader peaks suggest decrease in the crystallite size and crystallinity with increasing grinding time. The decrease in the crystallite size is also corroborated from the SEM images (Fig. S4, ESI $\dagger$ ), where bigger particles transform to plate shaped microcrystals after 30 min grinding.

Previously reported photoreactive helical CP chains with well-aligned olefin groups in the 5 -Spym ligands, ${ }^{27}$ yielded $100 \%$ dimerized product upon UV irradiation. In this work, while powdered samples of $\mathbf{1}$ after $20 \mathrm{~min}$ and 25 min grinding resulted $40 \%$ and $59 \%$ dimerization respectively after $72 \mathrm{~h}$ of 


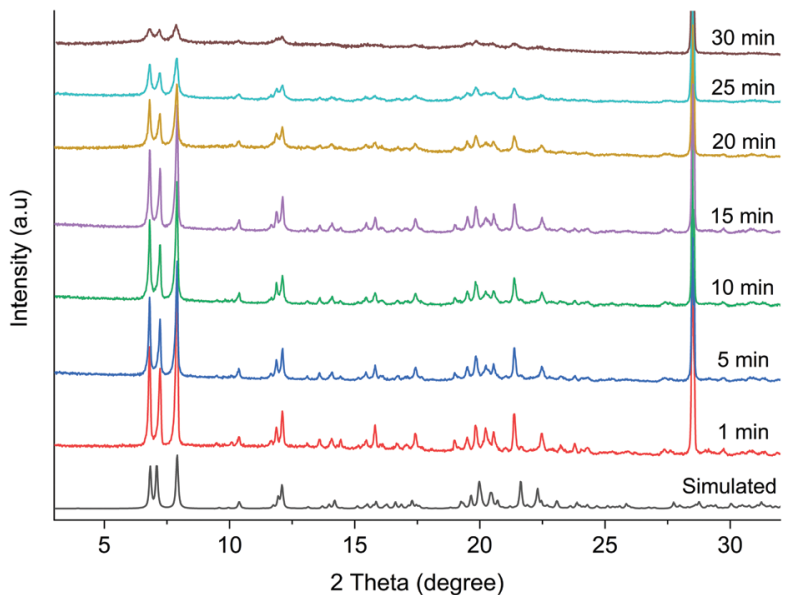

Fig. 3 The PXRD patterns of 1 at different grinding time along with the simulated pattern from the single crystal data.

UV irradiation, a maximum dimerization of $83 \%$ was only achieved for 30 minute grinding sample in $25 \mathrm{~h}$ of UV irradiation. Further, the single crystals heated to $150{ }^{\circ} \mathrm{C}$ for $30 \mathrm{~min}$ were found to be photo-inert under UV light. Thus, the photoreactivity is not due to heat generated by grinding.

Orderly alignments of the olefin pairs are required for the solid-state photochemical [2+2] cycloaddition reaction and this can be achieved only in the solids with long-range order. Usually, grinding of a solid is expected to reduce the particle size. Hence, the amount of photoproduct will increase due to increase in the surface area as UV light can penetrate better. In this current study, there is no perfect alignment of the olefin pairs and the long-range order seems to be reduced due to increased amorphization of the 30 min ground sample as evident from the broadening of the peaks in the powder X-ray diffraction in Fig. 3. Further analysis by high resolution transmission electron microscopy (HRTEM) was done to examine the crystalline nature of the sample. The HRTEM images (Fig. S5, ESI $\dagger$ ) clearly show lattice fringes and crystallinity, inferring that the reduced size in the crystallite size did not destroy the crystallinity completely. In order to investigate the volume expansion, if any, by grinding, the densities of the powders at different time of grinding were measured by neutral buoyancy method and the results are plotted in Fig. 4. The trend highlights that grinding decreases the density of the sample and hence, increase the cell volume.

In order to get further insights into the nature of volume expansion, Pawley refinements were undertaken on all samples

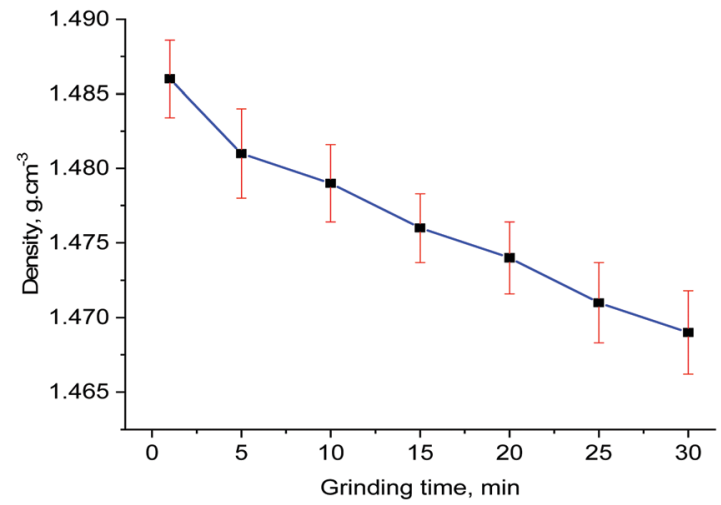

Fig. 4 A plot of measured densities of the ground samples with grinding time.

using the TOPAS program. ${ }^{28}$ The results are displayed in Table 1 which corroborates the results from the density measurements. The grinding time increases the lengths of $a$-axis while the helical $b$-axis remains relatively unaltered. The increase in $a$ axis lengths can be explained by the rotation of the helical chains along $b$-axis which brings the styryl arms closer together to have head-to-tail alignment, which in turn, satisfy the Schmidt's conditions for the photoreactivity. ${ }^{26}$ Apart from this, increased amorphization due to mechanical grinding could facilitate more rotational motion and the amorphous phase present could still give rise to head-to-tail alignment of the ligands. Also, the rotational motion and consequent photoreaction upon UV irradiation may occur on thin surfaces of the particles. This explains the enhanced photoreactivity of 30 min grinding sample with particle size around $11 \mathrm{~nm}$.

In summary, a helical CP was found to be photo-inert in the solid state as the olefin groups in the neighbouring styryl arms were not suitably aligned to under [2+2] cycloaddition reaction. However, the ground samples showed increased photoreaction with increasing grinding time, and quantitative consumption of olefin bonds were observed in $30 \mathrm{~min}$ of ground sample after $25 \mathrm{~h}$ of UV irradiation. The photoproduct is expected to have a two-dimensional structure. Movements of the functional groups have been observed in CPs in the solid state. ${ }^{15-21}$ Further, mechanical grinding has been known to promote pedal motion of crisscrossed olefin pairs, ${ }^{8-14}$ movements of molecules, ${ }^{29-31}$ and change in chemical composition. ${ }^{32}$ Large molecular movement of ladders in the crystal lattice by mechanical grinding was reported to facilitate quantitative photodimerization. ${ }^{33}$ In a rare case, here we observed that simple mechanical grinding induced

Table 1 Selected crystal data for 1

\begin{tabular}{|c|c|c|c|c|c|c|c|}
\hline Sample & $\mathrm{LP}-a, \AA$ & $\mathrm{LP}-b, \AA$ & $\mathrm{LP}-c, \AA$ & $\mathrm{LP}-\beta,^{\circ}$ & $V, \AA^{3}$ & $\begin{array}{l}\rho, \mathrm{g} \mathrm{cm}^{-3} \\
\text { (experimental) }\end{array}$ & $\begin{array}{l}\text { Crystallite size } \\
\text { (nm) }\end{array}$ \\
\hline 1 min grinding & $26.4759(5)$ & $9.1166(1)$ & $28.0833(5)$ & 111.524(1) & $6306.2(2)$ & $1.486(2)$ & $87.9(8)$ \\
\hline $10 \mathrm{~min}$ grinding & $26.5179(6)$ & 9.11383 & $28.0879(6)$ & $111.527(2)$ & $6314.7(3)$ & $1.480(2)$ & $66.4(6)$ \\
\hline $20 \mathrm{~min}$ grinding & $26.5310(7)$ & $9.1115(2)$ & $28.0967(6)$ & $111.565(2)$ & $6316.6(3)$ & $1.474(2)$ & $50.6(5)$ \\
\hline $30 \mathrm{~min}$ grinding & $26.540(1)$ & $9.112(3)$ & $28.096(9)$ & $111.50(3)$ & $6321.8(4)$ & $1.469(3)$ & $11.5(2)$ \\
\hline
\end{tabular}

Complete details about the TOPAS ${ }^{28}$ results are given in ESI (Table S1). 
cooperative rotational movements of the neighbouring helices in 1, which facilitates the alignment of olefin bonds as confirmed by the solid state [2+2] cycloaddition reaction under UV light. Unusually, grinding causes anisotropic volume expansion as evident from the density measurements and cell data.

This work was financially supported by the Ministry of Education, Singapore (Grant No. Tier 1 WBS R-143-000-A12-114 and R-143-000-B13-114). We acknowledge the help of Ms Geok Kheng for collecting the single crystal X-ray intensity data.

\section{Conflicts of interest}

There are no conflicts to declare.

\section{Notes and references}

‡ Crystal data for 1 at $100(2) \mathrm{K}$ (CCDC 1989895): $\mathrm{C}_{31.75} \mathrm{H}_{28} \mathrm{AgF}_{3} \mathrm{~N}_{2} \mathrm{O}_{3.75} \mathrm{PS}$, $M=725.46$; monoclinic, $P 2_{1} / n ; a=26.6378(6), b=9.0287(2), c=27.6480(6) \AA ;$ $\beta=110.8540(10) ; V=6213.9(2) \AA^{3} ; Z=8 ; \rho_{\text {calc }}=1.551 \mathrm{~g} \mathrm{~cm}^{-3} ; \mu=$ $0.824 \mathrm{~mm}^{-1} ; \mathrm{GOF}=1.032$; final $R_{1}=0.0532 ; \mathrm{w} R_{2}=0.0898$ [for 11716 data $I>2 \sigma(I)]$.

$\S$ Crystal data for $r c t t$-bpcb at 100(2) K (CCDC 1990101): $\mathrm{C}_{24} \mathrm{H}_{20} \mathrm{~N}_{4}, M=$ 364.44; monoclinic, $P 2_{1} / c ; a=10.4634(5), b=8.3919(4), c=10.5935(6) \AA$; $\beta=98.999(2) ; V=918.74(8) \AA^{3} ; Z=2 ; \rho_{\text {calc }}=1.317 \mathrm{~g} \mathrm{~cm}^{-3} ; \mu=0.080 \mathrm{~mm}^{-1}$; $\mathrm{GOF}=1.051$; final $R_{1}=0.0505 ; \mathrm{w} R_{2}=0.1336$ [for 2267 data $I>2 \sigma(I)$ ].

1 S. Erbas-Cakmak, D. A. Leigh, C. T. McTernan and A. L. Nussbaumer, Chem. Rev., 2015, 115, 10081-10206.

2 J. D. Dunitz, E. F. Maverick and K. N. Trueblood, Angew. Chem., Int. Ed. Engl., 1988, 27, 880-895.

3 C. S. Vogelsberg and M. A. Garcia-Garibay, Chem. Soc. Rev., 2012, 41, 1892-1910.

4 J. M. Abendroth, O. S. Bushuyev, P. S. Weiss and C. J. Barrett, ACS Nano, 2015, 9(8), 7746-7768.

5 M. K. Sharma and P. K. Bharadwaj, Inorg. Chem., 2011, 50, 1889-1897.

6 J. Harada and K. Ogawa, Chem. Soc. Rev., 2009, 38, 2244-2252.

7 T.-A. V. Khuong, G. Zepeda, C. N. Sanrame, H. Dang, M. D. Bartberger, K. N. Houk and M. A. Garcia-Garibay, J. Am. Chem. Soc., 2004, 126, 14778-14786.
8 J. Harada and K. Ogawa, J. Am. Chem. Soc., 2004, 126, 3539-3544.

9 J. Harada, M. Harakawa and K. Ogawa, CrystEngComm, 2008, $1777-1781$.

10 S. Galli, P. Mercandelli and A. Sironi, J. Am. Chem. Soc., 1999, 121, 3767-3772.

11 B. R. Bhogala, B. Captain, A. Parthasarathy and V. Ramamurthy, J. Am. Chem. Soc., 2010, 132, 13434-13442.

12 A. M. P. Peedikakkal and J. J. Vittal, Chem. - Eur. J., 2008, 14, 5329-5334.

13 Q. Chu, D. C. Swenson and L. R. MacGillivray, Angew. Chem., Int. Ed., 2005, 44, 3569-3572.

14 A. Chanthapally, W. T. Oh and J. J. Vittal, Chem. Commun., 2014, 50, 451-453.

15 S. Pérez-Estrada, B. Rodríguez-Molina, E. F. Maverick, S. I. Khan and M. A. Garcia-Garibay, J. Am. Chem. Soc., 2019, 141, 2413-2420.

16 S. L. James, C. J. Adams, C. Bolm, D. Braga, P. Collier, T. Friščić, F. Grepioni, K. D. M. Harris, G. Hyett, W. Jones, A. Krebs, J. Mack, L. Maini, A. G. Orpen, I. P. Parkin, W. C. Shearouse, J. W. Steed and D. C. Waddell, Chem. Soc. Rev., 2012, 41, 413-447.

17 D. Braga and F. Grepioni, Angew. Chem., Int. Ed., 2004, 43, 4002-4011.

18 A. V. Trask and W. Jones, Top. Curr. Chem., 2005, 254, 41-70.

19 A. L. Garay, A. Pichon and S. L. James, Chem. Soc. Rev., 2007, 36, 846-855.

20 C. Mottillo and T. Friščić, Molecules, 2017, 22, 144.

21 G. Kaupp, Curr. Opin. Solid State Mater. Sci., 2002, 6, 131-138.

22 H. Noji, D. Okuno and T. Ikeda, Chem. Sci., 2011, 2, 2086-2093.

23 K. M. Wiggins, J. N. Brantley and C. W. Bielawski, Chem. Soc. Rev., 2013, 42, 7130-7147.

24 M. K. Beyer and H. Clausen-Schaumann, Chem. Rev., 2005, 105, 2921-2948.

25 G. De Bo, Chem. Sci., 2018, 9, 15-21.

26 G. M. J. Schmidt, Pure Appl. Chem., 1971, 27, 647-678.

27 B. B. Rath, G. K. Kole and J. J. Vittal, Cryst. Growth Des., 2018, 18(10), 6221-6226.

28 A. A. Coelho, J. Appl. Crystallogr., 2018, 51, 210-218.

29 M. Nagarathinam and J. J. Vittal, Angew. Chem., Int. Ed., 2006, 45, 4337-4341.

30 M. Nagarathinam and J. J. Vittal, Chem. Commun., 2008, 438-440.

31 A. Chanthapally, W. T. Oh and J. J. Vittal, CrystEngComm, 2013, 15, 9324-9327.

32 G. K. Kole, G. K. Tan and J. J. Vittal, Org. Lett., 2010, 12, 128-131.

33 H. A. Al-Mohsin, A. AlMousa, S. A. Oladepo, A. S. Jalilov, M. Fettouhi and A. M. P. Peedikakkal, Inorg. Chem., 2019, 58, 10167-10173. 